\title{
On Subject It-Extrapositions: Evidence from Present-Day English
}

\section{María Ángeles Gómez-González Universidad de Santiago de Compostela}

\begin{abstract}
This paper reports some results from a bigger project analysing the relevance of Theme, i.e. clause initial position, in Present-day English (PresE). Our aim is to explore the formal features, the communicative properties and the frequencies of one thematic device, It-extrapositions of the type It is strange that the duke gave my aunt that teapot, in the Lancaster Spoken English Corpus (henceforth LSEC). 105 tokens of these constructions were studied, which represented $2.6 \%$ of the overall Themes in LSEC.

It is argued that the use of $I t$-extrapositions obeys three different, though interrelated, phenomena: (i) the principle of End Weight; (ii) the Given-BeforeNew principle; and (iii) Theme. As a conclusion, it is suggested that the raison d'être of this device is to act in two capacities: (1) an objective one, expressing an 'objectified', or depersonalised, modality or modulation, and (2) a subjective one, infusing the speaker's angle, or point of view, with thematic highlighting.
\end{abstract}

\section{Formal structure of $I t$-Extrapositions}

Unmarked It-extrapositions ${ }^{2}$ move a rankshifted nominal clause out of Subject position in the Head clause to the right of its predicate, replacing it with the dummy pronoun it. As a result, the main clause, with $I t$ as its Subject Theme 2 (i.e. initial constituent of the initial clause in a clause complex), becomes the Thernel (initial clause in a clause complex) of 
the whole clause complex and the extraposed clause its Rhemel (final clause in a clause complex), as illustrated in (1) below (cf. Huddleston 451-2; McCawley 95; Collins, 2):

It is strangethat the duke gave my aunt that teapot

\section{Theme2Rheme2 Theme2 Rheme2}

Theme1

Rheme1

In some cases the extraposition is obligatory as in constructions with it is a fact or when the extraposed clause itself contains a subordinate clause and the type of subordination is the same at both levels (e.g. *To avoid the speculation that for Richard Gardiner Casey to approve his son's wish to serve in what was expected to be a short war while using his own influence to minimise the dangers to be faced by his son would have been in character is difficult, Collins ibid.). But, on other occasions, extrapositions are blocked by grammatical factors, such as, for example, when a dominant predicate contains a subordinate clause or an identified predicate Complement. Likewise, under certain restrictive conditions extrapositions may involve the shifting of units other than nominal clauses, such as prepositional phrases or noun phrases containing the and a restrictive relative clause (e.g. It's astonishing the dedication he shows; it appalled us the way he spoke to his wife, in response to What a lot of dedication he shows; How (rudely) he spoke to his wife, cf. e.g. Collins 16 Footnote 3; McCawley, 96). These marginal cases were not considered in this study for the sake of simplicity. The same applied to extrapositions like (2) below, moving a constituent out of Object position over another Complement in the Head clause replacing it with the dummy it, which were disregarded in this analysis on the assumption that they affect the Rheme, rather than the Theme, of Head clauses in clause complexes.

(2) | 'Israel | was ${ }^{\circ}$ making it a'bundantly "clear to ${ }^{\circ}$ wards the ${ }^{\circ}$ end of the ${ }^{\circ}$ week $\mid$ that the re-maining Shi'ites / -were to be released / anyway / not as ${ }^{\circ}$ any ${ }^{\circ}$ conse ${ }^{\circ}$ quence of the 'hijack / but 'purely as a 'function of the -level of trouble / in _South Lebanon I (SECA07: 044)

It is also necessary at this stage to differentiate the phenomenon of extraposition from three superficially similar clausal structures:

(i) impersonal sequences having neutral it as Subject Theme such as It was getting dark (SECAPT04: 072), It is now ten past eight (SECBPT02: 205);

(ii) identifying constructions having a generic anaphoric it as Subject ID/VL (Identified/Value) such as e.g. It could have been an outsider (SECJPT03: 023);

(iii) right-dislocations, where, typically, a NP is shifted outside, and to the right of, the main clause, and where the pronoun it, if present, is referential (cataphoric), in contrast with its non-referential anticipatory nature in the extraposed construction (e.g. It is nice the rose). 
The first two cases were here regarded as constructions with unmarked Themes that place within their Rhemes, the unmarked locus of focal stress, the information which is 'newsworthy'. By contrast, right-dislocations and extrapositions were treated as instances of Special Themes, because both imply a process of substitution of the Theme and its shifting to the right of the main predicator. Admittedly, the identificational criteria of extrapositions, i.e. substitution of Theme by a dummy element and right-shifting and rankshifting of a nominal clause, do not suffice to differentiate all instances of this type of Special Theme construction from right dislocations. Firstly, they apply to prototypes only. Secondly, extraposed clauses exhibit varying degrees of nominalisation. And thirdly, in a given context, the status of an introductory it, i.e. whether referential or not, may be ambivalent -especially given the fact that the primary function of dislocations is to disambiguate this ambivalence. This would leave us only with the criterion of prosody, whereby prototypical right-dislocated clauses would be expected to be spoken with a compound intonation Nucleus and extrapositions to have a simple Nucleus. However, in practice, this difference is again anything but clear-cut, for in many tokens of Subject extrapositions there is a tone group boundary separating the Head from the extraposed clause (see Quirk et al. 1985: 1393).

With these provisos, Subject extraposition were here considered as a special type of Theme construction in its own right, deserving a corpus-based analysis. 105 tokens were found in the Lancaster Spoken English Corpus (LSEC), a machine-readable corpus comprising 49,285 words broken down into ten textual categories of spoken PresBE (see Table 1 below): (i) Commentary (A); (ii) News broadcast (B); (iii) Lecture Type I -aimed at a general audience (C); (iv) Lecture Type II -aimed at restricted audience (D); (v) Religious broadcast (E); (vi) Magazine style reporting (F); (vii) Fiction (G); (viii) Poetry (H); (ix) Dialogue (J); (x) Propaganda (K). ${ }^{3}$

Table 1 SEC Corpus $(49,285$ words $)$

\begin{tabular}{|c|c|c|c|c|c|c|}
\hline TEXT & CATEGORY & DATE & $\begin{array}{l}\text { LENGTH } \\
\text { min: sec. }\end{array}$ & $\begin{array}{c}\# \\
\text { SPEAKERS }\end{array}$ & $\begin{array}{c}\# \\
\text { WORDS }\end{array}$ & $\begin{array}{c}\% \\
\text { WORDS }\end{array}$ \\
\hline $\mathrm{A} 01-\mathrm{A} 12$ & Commentary & $\begin{array}{l}11-24-84 \\
06-22-85\end{array}$ & $64: 30$ & 12 & 9,066 & 18,4 \\
\hline B01-B04 & $\begin{array}{c}\text { News } \\
\text { Broadcasts }\end{array}$ & $\begin{array}{l}11-24-84 \\
01-14-86\end{array}$ & $29: 12$ & 15 & 5,235 & 10,6 \\
\hline $\mathrm{CO} 1$ & $\begin{array}{l}\text { Lecture Type I } \\
\text { general } \\
\text { audience }\end{array}$ & $11-20-85$ & $30: 00$ & 1 & 4,471 & 9,1 \\
\hline D01-D03 & $\begin{array}{c}\text { Lecture Type II } \\
\text { Open } \\
\text { University } \\
\text { Audience }\end{array}$ & - & $57: 00$ & 3 & 7,451 & 15,1 \\
\hline $\mathrm{E} 01-\mathrm{E} 02$ & $\begin{array}{l}\text { Religious } \\
\text { Broadcast }\end{array}$ & $\begin{array}{l}11-26-85 \\
11-27-85\end{array}$ & 11: 18 & 2 & 1,503 & 3,1 \\
\hline
\end{tabular}




\begin{tabular}{|c|c|c|c|c|c|c|}
\hline F01-F04 & $\begin{array}{c}\text { Magazine-style } \\
\text { reporting }\end{array}$ & $\begin{array}{c}11-24-84 \\
12--86\end{array}$ & $25: 30$ & 14 & 4,710 & 9,6 \\
\hline G01-G05 & Fiction & $\begin{array}{c}06-25-85 \\
01-28-87 \\
01-26-86\end{array}$ & $46: 25$ & 5 & 7,299 & 14,8 \\
\hline H01-H05 & Poetry & $11-26-86$ & $9: 00$ & 5 & 1,292 & 2,6 \\
\hline J01-J06 & Dialogue & $\begin{array}{c}12-82 \\
03-11-87\end{array}$ & $37: 28$ & 9 & 6,826 & 13,8 \\
\hline K01-K02 & Propaganda & $\begin{array}{c}01-18-87 \\
01-25-87\end{array}$ & $8: 41$ & 2 & 1,432 & 2,9 \\
\hline
\end{tabular}

In LSEC It-extrapositions typically right-shifted finite nominal that-clauses (54\%), of which $93 \%$ were declaratives with or without that (e.g. (3: i, ii)) and a minority interrogatives (e.g. (3: iii)).

(3) (i) | he's [Arafat] is seeking ${ }^{\circ}$ take the - -boldest ${ }^{\circ}$ move of his life | and his de cision | ${ }^{\circ}$ seems to be ${ }^{\circ}$ going down , well $\mid$ with his con ${ }^{\circ}$ stituency at large | if 'not with ${ }^{\circ}$ all the _.groups | wi thin the $\mathrm{PL}_{4} \mathrm{O} \mid-$ like at ${ }^{\times}$all ${ }^{\circ}$ party ${ }^{\circ}$ conferences $/{ }^{\circ}$ round the , world there's a par-ticular_atmosphere $\mid{ }^{\circ}{ }^{\circ} \mathrm{cama}$ rade ${ }^{\circ}$ rie $\mid$ but it - does seem $\mid$ that ${ }_{v}$ this ${ }^{\circ}$ meeting | is | a little bit special | (SECAPT02:035)

(ii), well | they 'searched me $\mid$ of 'course I'didn't have any 'weapons $\mid$ just a 'camera $\mid \uparrow i t$ 's funny they let me keep it | (SECBPT03: 026)

(iii) $\mid$ or - could it be $\mid$ that ${ }^{\circ}$ when you look - back $\mid$ at the - sporting _year $\left|' 198^{-1}-6\right|$ ${ }^{\circ}$ etched in'delibly on your--memory $\mid$ will be the -frighteningly $\mid$ dra-matic moment | when ${ }^{\circ}$ Nigel - Mansell's | tyre ${ }^{\circ}$ burst $\mid$ at $-200^{\circ}$ miles an, hour $\mid$ to de ${ }^{\circ}$ ny him $\mid$ the ${ }^{\circ}$ World _Motor Racing 'Championship | or ${ }^{\circ}$ those _classic en'counters / be ${ }^{\circ}$ tween ${ }^{\circ}$ Dancing ${ }^{\prime}$ Brave | and -Shahra'stani ('SECJ01: 014-20)

In their turn, rightshifted non-finite infinitival clauses, generally introduced by to $(96 \%)$ (e.g. (4: i) ) and occasionally by for (4\%) (e.g. (4: ii)), ${ }^{4}$ or gerundial clauses (e.g. (5)) were more peripheral than finite ones (39\% and $7 \%$, respectively):

(4) (i) | and it is 'very 'difficult $\mid$ to ${ }^{\circ}$ work $\mid$ Lunder con'ditions like 'that $\mid$ when the 'temperature's ${ }^{\circ}$ what $\mid$ fifty degrees 'centigrade sometimes | (SECJPT06: 228)

(ii) well $\mid$ 'as it worked 'out in ${ }^{\circ}$ fact $\mid$ 'they didn't ${ }^{\circ}$ pay them selves $\mid$ it was the 'company that $\mid$ they 'worked ${ }^{\circ}$ for $\mid$ you ${ }^{\circ}$ see 'they worked at the ${ }^{\circ}$ Hotel ${ }_{v}$ Hilton $\mid$ ${ }^{\circ}$ and it was in their ${ }^{v}$ interests | for them to learn ${ }^{\circ}$ English $\mid$ so the 'company ssponsored them | to _come / and have _lessons with , me | so I | (SECJ06: 102)

(5) | it's 'not a ${ }^{\circ}$ bit of 'good $\mid$ 'mooching a bout $\mid$ and 'moaning | and 'saying, -this vweather |-what a climate $_{\wedge}$ and ${ }^{\circ}$ so on $\left.\right|^{\circ}$ this is $\uparrow^{\prime}$ (SECGPT05: 009) 
The percentages given above suggest that, as reported by Collins (1994: 11), nominal finite and infinitival clauses extrapose more freely than gerundials. The fact that, like noun phrases, -ing clauses were generally resistant to being extraposed, confirms that the latter are more highly nominalised than finite or infinitival clauses (they also invert more readily with the operator in interrogatives and can take a possessive expression as a Subject). Quirk et al. (1393) claim that gerundial extraposed clauses are uncommon outside informal speech and Huddleston (452) remarks that they are more acceptable when both the -ing clause and the matrix clause are relatively short. Our results confirmed Huddleston's hypothesis since the lexical density, i.e. proportion of content words, of the Themes and Rhemes of extrapositions in LSEC was 3.5-7, respectively.

As to the matrix predicate of extraposed constructions in LSEC, it normally showed the Subject-Predicator-Subject Complement pattern $(71 \%)$, with the Complement most commonly realised as an adjectival phrase (54\%) as in (6: i), and less often as a noun phrase (37\%) as in (6: ii) or as an adverbial phrase (9\%) as (6: iii).

(6) (i) [change of speaker: Kevin Geary] 'well $\mid$ our re'view $\mid$ is -almost complete now but it's - really / only ${ }^{\circ}$ right and proper | that the - old ${ }^{\circ}$ year $\mid$ should go _out with a bang | and 'heavyweight 'boxing | (SECFPT04: 286)

(ii) | it's a ${ }^{\vee}$ useful re $e^{\circ}$ minder $\mid$ that ${ }^{\vee}$ some ${ }^{\circ}$ scientists $\mid{ }^{\circ}$ find _Don ${ }^{\prime}$ Cupitt ${ }^{\circ}$ unscien,tific $\mid$ the de-bate $\mid$ goes on | (SECAPT01: 77)

(iii) $\mid$ it was e'nough $\mid$ to ex - pose the ,crisis $\mid$ in the 'relevance of 'art $\mid \downarrow$ how'ever $\mid$ ${ }^{\circ} \mathrm{Dada}$ - did put_forward_some | ${ }^{\circ}$ positive proposals | (SECDPT1: 119)

The second most common type of extraposed pattern in LSEC (20\%) was SubjectPredicator (the predicator being passive $(6.7 \%)$ or active $(93.3 \%)$, e.g. (7: i, ii) respectively), the latter being occasionally modified by an Adjunct.

(7) (i) $\mid \uparrow_{i t}^{\prime}{ }^{\prime}$ been ${ }^{\circ}$ widely su vggested $^{\circ}$ here $/$ that the ${ }^{\circ}$ great im balance in ${ }^{\vee}$ this $\mathrm{x}^{\circ}$ change $1{ }^{\circ}$ might have prompted the ${ }^{\circ}$ Beirut hijackers | into 'thinking | they could ${ }^{\circ}$ force ${ }^{\circ}$ Israel | into re,leasing | _more ${ }^{\circ}$ Arab prisoners | (SECPT04: 041)

(ii) |'eastern block 'influence in`side UNESCO $\mid$ is now too 'great $\mid \downarrow$ the _government be-lieves | and re'form from in ${ }^{\circ}$ side is im'possible | so it 'seems the ${ }^{\circ}$ widespread ${ }^{\vee}$ pressure to stay in $\mid$ has been re,sisted $\mid$ (SECBPT03:087)

In this type non-extraposed counterparts are normally not available ( ?That the great imbalance in this exchange might have prompted the Beirut hijackers into thinking they could force Israel into releasing more Arab prisoners has been widely suggested; *That widespread pressure to stay in has been resisted seems). The third pattern was SubjectPredicator-Object/Complement ((5\%), e.g. (8) where a Range is acting as Complement) and the fourth is Subject-Predicator-Indirect Object (Direct Object) (Agent) ((3\%), e.g. (9)).

(8) the ${ }^{\circ}$ Nova ${ }^{\circ}$ Park Elysee in ${ }^{\vee}$ Paris $\mid{ }^{\circ}$ costs —three, thousand $\mid{ }^{\circ}$ nine hundred _pounds $\mid$ a day $\mid$ whereas it ${ }^{\vee}$ only ${ }^{\circ}$ costs $\mid{ }^{\circ}$ six hundred and ${ }^{\circ}$ fifteen $\uparrow$ 'dollars $a{ }^{\circ}$ day $\mid$ to 
${ }^{\circ}$ Stay in the 'world's most ex ${ }^{\circ}$ pensive vhospital | ${ }^{\circ}$ needless to ${ }^{\circ}$ say in ${ }^{\circ} \mathrm{Cali}$ fornia | (SECFPT03: 079)

(9) | it was then pointed ${ }^{\vee}$ out to the ${ }^{\circ}$ officer $\mid$ by a ${ }_{\checkmark}$ French ${ }^{\circ}$ journalist $\mid$ that the Al'gerian vwar was 'lost in 'Paris |'not in Al giers | (SECAPT09: 075)

Two reasons suggest themselves for the infrequency of these last two types of extrapositions. First, the matrix predicates displaying patterns three and four were often, though not always (e.g. costs in (8) above), of a dynamic, rather than of a stative, nature, and so they were more likely to favour animate non-verbal Subjects than clausal (especially finite) ones, the latter being the typical Subject of $I t$-Subject Extrapositions. The second reason was the effect of the principles of end Weight and/or end Focus. The predicates associated with these two patterns, i.e. material or verbal, were normally 'heavier' and more informative than those in the first two patterns, i.e. relational or mental, and therefore the pressure for extraposition was weaker.

Finally, moving on to the extraposed clause itself, as already mentioned earlier in this section, it always acted as the Subject of the main clause and so collaborated to display an unmarked mood pattern in prototypical extrapositions. However, there were some peripheral instances of marked Subject extrapositions in LSEC (10.5\%), i.e. extrapositions with fronted Themes, that is to say, constituents that were preposed to clause initial position by a process of fronting, which thereby: (i) were explicitly foregrounded as a point of departure for the message; (ii) added some sort of contrast; and (iii) were frequently marked off by being spoken on a separate tone group (cf. Halliday 1967, 1994).

In some cases extrapositions with fronted Themes resulted from the presence of a Beta Theme (i.e. a Dependent clause preceding the Head clause of the extraposed construction), as in (10: i) (33\%), or from the fronting of an Adjunct before the dummy Subject It (67\%), as in (10: ii), where neither, at the same time, triggers the phenomenon of Subject/Process inversion:

(10) (i) $\mid$ but al $\uparrow$-though ${ }^{\circ}$ Fine_Gael and_Labour $\mid \vee$ have lost ${ }^{\circ}$ ground to the oppo ${ }^{\circ}$ sition $\mid$ it's $\uparrow$-far from, clear | that _Fianna ${ }^{\circ}$ Fail would ${ }_{1}$ sweep the ${ }_{v}$ board $\mid$ if it were _called to'morrow |(SECBPT02: 138-41)

(ii) | ${ }^{\circ}$ neither in Hong ,Kong | nor ${ }^{\circ}$ anywhere 'else | does it-make_sense to 'specify | as an -aim of policy $\mid$-on the, basis of - soap-ope,ratic - intu,ition a,lone $\mid$ a par ticular ,ratio of do-mestic pro ${ }^{\circ}$ duction | to - total consumption | (SECCPT01: 240-3)

\section{Discourse function of $I t$-Extrapositions}

In what follows it will be argued that the discourse motivation of $I t$-extrapositions obeys three different, though interrelated, phenomena: (i) the principle of end Weight; (ii) the Given-Before-New principle; and (iii) Theme. The first two explain the end-positioning of material in extraposition, while the last one accounts for its initialisation. The fact that in PresE Subject clauses tend to be moved to the right reflects two things: 
(i) a strong tendency to avoid long units at the beginning of clauses (i.e. end Weight principle);

(ii)a preference for the 'Given-before-New' ordering of information (i.e. end Focus principle).

My findings in LSEC provided support to posit the End-Weight Principle and its concomitants, end Focus and ease of information processing, as explanatory in cases of It-extrapositions, in that:

(i) extraposed clauses tended to be 'heavier' (i.e. have a higher lexical density, cf. Francis 1989, Collins 1984) than dominant predicates (8.6 vs. 3.6);

(ii) there was a more even distribution of weight between the rankshifted and the dominant predicate in non-extraposed sentences;

(iii) dominant predicates were generally heavier in non-extraposed than in extraposed constructions;

(iv) English disfavours clauses with clausal Subject in initial position followed by a comparatively light matrix predicate.

In addition to the principle of end Weight, extrapositions in LSEC reflected a Givenbefore-New array of information. For, informatively speaking, in most cases the newsworthy bit of information was placed in the extraposed clause, that is, within the Rhemel of the clause complex and thus was marked as New, getting unmarked focal stress. Witness in this respect (11) below:

(11) | it's ${ }^{\circ}$ quite 'likely | that a'nother old ${ }^{\circ}$ timer $\mid$ the Prime ${ }^{\prime}$ Minister $\mid$ Mr 'Tikhanov | will re_tire, soon $\mid$ and be re,placed $\mid$ by a ${ }^{\circ}$ young 'technocrat $\mid \uparrow$ with the _Gorbachev, style | the 'phrase that struck ${ }^{\circ}$ me with ${ }^{\vee}$ most ${ }^{\circ}$ force $\mid$ in his ${ }^{\circ}$ recent ${ }^{\prime}$ speech $\mid$ was ${ }^{\prime}$ when he was ${ }^{\circ}$ talking $a^{\circ}$ bout the -need $\mid$ for a ${ }^{\circ}$ psycho ${ }^{\vee}$ logical ${ }^{\circ}$ change | from_top to bottom $\mid$ in _Soviet so,ciety $\mid$ and he ${ }^{v}$ pushed this ${ }^{\circ}$ thought $\mathrm{a}^{\circ}$ gain this ${ }^{\circ}$ week $\mid$ when he ${ }^{\prime}$ called $\mid$ the ${ }^{\circ}$ heads of ${ }^{\circ}$ all the state ${ }^{\vee}$ media ${ }^{\circ}$ organi ${ }^{\circ}$ sations | ${ }^{\circ}$ in for a 'pep talk | it was 'their ${ }^{\vee}$ job he ${ }^{\circ}$ said $\mid$ to ex'pose in adequacies in the 'system $\mid$ by ${ }^{\circ}$ changing _people's per,ceptions $\mid$ (SECAPT11: 025-40)

In (11) above the thematic matrix clause 'it's quite likely' is informatively poor as compared with the information coded in the rhematic extraposed clause, where it is announced that the current Prime Minister of the Soviet Union, Mr. Tikhanov (expressed by a definite proper noun whose referent is contextually inferrable), may be replaced by a young technocrat, who is presented as New (indefinite expression with focal stress) and whose referent was up to that point in discourse New, to become Topic over the subsequent discourse span. In contrast, when the Theme2-Rheme2 pattern of a Subject rankshifted clause in a clause complex encodes recoverable information the tendency is for it to remain in initial position, rather than to be extraposed to the rhematic slot. Importantly enough, however, it seems to me that the newness of extraposed clauses does not reside in the individual informative status of one particular constituent, but rather in 
the structure itself, that is to say, in the predicative link established between the Theme1 and the Rhemel of the construct. This link usually conveys unrecoverable, or new, information, while the referents of the participants and circumstances of extrapositions themselves are often presented as recoverable (i.e. realised by definite, deictic or pronominal forms, especially in infinitival clauses).

It only remains to analyse the discourse relevance, if any, of the thematic matrix clause in Subject extrapositions. My findings in LSEC confirmed once more Halliday's (1994: 322-24) prediction that Subject extrapositions code some sort of interpersonal meaning. The clausal Theme of Subject extrapositions in LSEC had the communicative effect of enabling speakers to express an 'objectified', or depersonalised, modality or modulation (they were introduced by impersonal it) on the ensuing Rheme and/or discourse. Indeed, LSEC speakers chose extrapositions in two capacities:

(i) in $15 \%$ of all cases, to project some meaning or wording in order to avoid an unqualified claim (e.g. it seems that...) or to ascribe to an unspecified source the responsibility for an assertion (e.g. it is said that...);

(ii)in the remaining $85 \%$, to thematise their angle, or point of view, along different values of typically modality (in (a) below) or less commonly of modulation (in (b) below), as illustrated below:

(a) modality (57\%), when assessing the likelihood or usuality of an event or when predicating the ease or difficulty of an action, as in:

(1) \pm possible $(32 \%)$ :

(12) the 'students will have two months off in the 'summer $\mid \uparrow$ but $\mid$ the terms are just 'really too long | by the time you hit $\uparrow$ 'mid $^{\circ}$ term | after about the -tenth or $\mathrm{e}^{\circ}$ leventh -week $\mid$ the 'students are really at $\mid$ an 'all-time 'low $\mid$ and it's very 'difficult to motivate them $\mid{ }^{v}$ into / into, studies $\mathrm{a}^{\circ}$ gain | (SECJPT06: 273)

(2) \pm probable $(24 \%)$

(13) | 个it may_well'be | that -oil and gas | will be 'so ${ }^{\circ}$ much 'more ${ }^{\circ}$ valuable in the future $\mid$ even $a^{\vee}$ llowing $\mid$ for the interest ${ }^{\circ}$ factor $\mid$ that ${ }^{\circ}$ has to be taken into a,ccount $\mid$, in such ${ }^{\circ}$ calcu,lations $\mid \uparrow_{\text {that }}$ governments $\mid$ should limit pro duction ${ }^{\vee}$ now $\mid$ and ${ }^{\circ}$ possibly also en ${ }^{\circ}$ courage imports |(SECCPT01: 425)

(3) \pm certain $(44 \%)$

(14) | it's been taken for 'granted | what'ever the $\uparrow$ 'party in -office | $\downarrow$ that the - Secretary of State for 'Energy |'or in'deed the - Cabinet it'self | must de- termine the _size / of the - nuclear power 'programme | the _choice of re'actor $\mid$ - - and the appropriate structure | for the - nuclear industry | (SECCPT01: 117)

(b) modulation (23\%), when imposing a requisite or asserting the desirability of an action, as in: 
(1) \pm desirable $(92 \%)$

(15) | it's just a pity | ${ }^{\circ} \mathrm{Greg}{ }^{\vee}$ Norman | doesn't qualify | [change of speaker: Kevin Geary] (SECFPT04: 142)

(2) \pm required $(8 \%)$

(16) | but it was 'part of the Muslim - law_there that the --women | _wore | ${ }^{\circ}$ those | — things to cover them_selves | (SECJPT06: 363-4)

In addition, I noted that in LSEC matrix predicates of Subject extrapositions displaying the patterns Subject-Predicator and Subject-Predicator-Complement normally involved some sort of projection ${ }^{5}$ or modulation ${ }^{6}$ of finite extraposed clauses. The latter tended to express facts, and so their factual nature made them liable to be projected or judged. In turn, when these two matrix predicate patterns extraposed infinitival clauses, they concerned different values of thematic modality (2.4: 46) above ( ). This result accords well with the action-like nature of infinitives, since degrees of possibility, probability or certainty are congruently applied to actions, rather than to facts. Likewise, my findings corroborate Mair's (25) claim that infinitival Subject clauses are only extraposed by predicates expressing some physical process, rather than by those used to judge the truth or likelihood of specific propositions or events, which would rather extrapose fact-like finite clauses.

As to the classes of Themes It-extrapositions tended to co-occur with, it was found that they had a tendency to involve just Topical Themes (i.e. Participants, Processes, Qualities and Circumstances) (66\%), or, less frequently (34\%), Multiple Themes (i.e. Topical Themes preceded by interpersonal and/or textual elements) concerning Logical Themes (i.e. clause initial textual elements) (28\% Structural, 5.7\% Conjunctive Adjuncts and $1.9 \%$ Continuatives) ${ }^{7}$. Only $10 \%$ co-occurred with Interpersonal Themes (4\% Modal Adjuncts, $6 \%$ Vocatives), which were used to reinforce the 'subjective' orientation of some extrapositions.

In addition, Subject extrapositions were mainly used in reconstructive texts (i.e. texts in which language is employed to monitor reality (as in e.g. reports or commentaries) or to recreate it (as in e.g. Poetry, Fiction stories etc.) cf. Martin 1984a, b) (42.9\%)). Some of these texts were in principle intended to be objective such as some (A) Commentaries $(17.1 \%)$ or (B) News reports $(13.3 \%)$, but others were purposely subjective such as $(\mathrm{G})$ Fiction (12.4\%) (and also some (A) Commentaries).

\section{Conclusion}

It has been argued that Subject $I t$-Extrapositions tend to right-shift finite nominal thatclauses and have a matrix predicate with the Subject-Predicator-Subject Complement pattern. In addition, our exposition has shown that this thematic device acts in two communicative capacities: an objective and a subjective one. On the one hand, 
extrapositions serve the semantic role of 'objectifying' a modality, that is to say, they are used as a way of either averting the responsibility for an assertion or of claiming objective necessity or certainty for what in fact could be regarded a matter of opinion. And, on the other hand, they fulfil the communicative role of foregrounding the modal expression thematically, by placing it in a clause superordinate to, and preceding, that expressing the rhematic and newsworthy proposition.

In keeping with this, Subject extrapositions were reported as popular in subjective and objective reconstructive LSEC texts. They allowed commentators and fictional characters to foreground their perspective on the reality they were monitoring and, at the same time, they permitted news readers to move away from any responsibility for what they were reporting. Likewise, not infrequently, in constructive texts (i.e. texts devised to construct a 'new' reality) (33\%), It-extrapositions came in handy to project and thus depersonalise some general statement, hope, feeling, etc. and/or to avoid an unqualified claim (Lectures $(17.1 \%)$, Magazine (15.2\%) and Religious Broadcasts (1\%)); whereas in Dialogues $(23.8 \%)$, their rather frequent use obeyed the speaker's intention to highlight the modulation and/or modalisation of facts and acts as the relevant concern of her/his collaborative addressee.

In sum, our findings about the two-fold communicative quality of Subject Itextrapositions prove Whittaker's (112) Evaluative Ideational Themes to be a felicitous label for these constructions. For, as pointed out by Halliday (211), these contructs constitute 'a semantic region where (...) the ideational and the interpersonal [functions], overlap', since, as remarked by by Downing (174), they 'are not the speaker's comments on the process but form part of the content of the clause itself'.

\section{Notes}

1. The research reported here is part of Gómez-González (1996). The project has been supported by grants from the Xunta de Galicia and from the the Spanish Ministry of Education and Science (Dirección General de Investigación Científica y Técnica (DGICYT), grants numbers PB90-0370 and PB94-0619). I am also indebted to professors C. S. Butler, T. Fanego, C. Cadarso and Bari Samitta for useful comments on the (pre)final draft of this paper. Any errors or shortcomings are of course my exclusive responsibility.

2. Markedness here refers to probability of choice, that is, the probabilities of choosing terms in grammatical systems. (cf. Davison 833; Kies 73 fn. 2). The implication is that systems tend towards one or other of just two types of choices: (i) equiprobable (i.e. 0.5/0.5); (ii) skew (e.g. $0.9 / 0.1)$. While equiprobable choices have no unmarked term, the skew ones have both unmarked and marked terms. As suggested by Kies (74), marked options are here regarded to display three features: (i) comparatively lower frequency of occurrence; (ii) comparatively higher structural complexity; (iii) more restricted distribution in definable environments.

3. SEC contains one more category, namely Miscellaneous ((M) 3352 words). This was discarded from this analysis because it did not refer to a specific text type, but comprised nine heterogeneous samples (viz. John Betjeman, Motoring News, two Weather Forecasts, two Programme News, Oratory, Travel Roundup), which in my view are already represented in the other ten types. 
4. According to Mair (42) for generally denotes animate experiencers, or beneficiaries, or at least entities metaphorically construed as mind-possessing. For may also introduce a Complement (e.g. It was important for my mother that the duke gave her that teapot) or a Complementiser of the superordinate clause (e.g. It is incredible for John to have come). No samples of these were found in LSEC.

5. Projection and expansion name two types of logico-semantic structural relations holding between processes. In projection the reporting clause 'instantiates' the reported clause as a locution (") or as an idea ("). By contrast, in expansion a process 'expands' another by: (i) elaborating it $(\Rightarrow$ (i.e. re-stating it, specifying it or commenting it); (ii) extending it $(+)$ (i.e. adding some new element, and exception or an alternative to it); or (iii) enhancing it (x) (i.e. qualifying it with some circumstantial feature).

6. Modulation refers to different degrees of inclination and obligation.

7. Table 2 below (based on Halliday $48 \mathrm{ff}$.) sets out the components of a Multiple Theme:

\section{Table 2 Components of a Multiple Theme}

\begin{tabular}{|c|c|c|}
\hline metafunction & component of Theme & Examples \\
\hline \multirow[t]{2}{*}{ textual } & Continuative & yes, no, well, oh, now \\
\hline & $\begin{array}{l}\text { Structural } \\
\text { conjunction } \\
\text { co-ordinator } \\
\text { subordinator } \\
\text { WH-relative } \\
\text { definite } \\
\text { indefinite }\end{array}$ & $\begin{array}{l}\text { and, or, nor, neither, but, yet, so, then } \\
\text { when, because, though, if, even if, given that } \\
\text { which, who, that, whose, when, where, why, how } \\
\text { whatever, whichever, whoever, whosoever, whenever }\end{array}$ \\
\hline & $\begin{array}{l}\text { Conjunctive Adjunct } \\
\text { elaborating 'i.e. e.g.' } \\
\text { appositive 'rather' } \\
\text { corrective 'rese' } \\
\text { dismissive 'in any case' } \\
\text { summative 'in short' } \\
\text { verifactive 'actually' } \\
\text { extending 'and' } \\
\text { additive 'and' } \\
\text { adversative 'but' } \\
\text { variative 'instead' } \\
\text { enhancing } \\
\text { temporal 'then' } \\
\text { comparative 'likewise' } \\
\text { causal 'so' } \\
\text { conditional '(if) ... then' } \\
\text { concessive 'yet' } \\
\text { respective 'as to that' }\end{array}$ & $\begin{array}{l}\text { that is, in other words, for instance } \\
\text { or rather, at least, to be precise } \\
\text { in any case, anyway, leaving that aside } \\
\text { briefly, to sum up, in conclusion } \\
\text { actually, in fact, as a matter of fact } \\
\text { also, moreover, in addition, besides } \\
\text { on the other hand, however, conversely } \\
\text { instead, alternatively } \\
\text { meanwhile, before that, later on, next, soon, finally } \\
\text { likewise, in the same way } \\
\text { therefore, for this reason, as a result, with this in } \\
\text { mind } \\
\text { in that case, under the circumstances } \\
\text { nevertheless, despite that } \\
\text { in this respect, as far as that's concerned }\end{array}$ \\
\hline
\end{tabular}




\begin{tabular}{|c|c|c|}
\hline \multirow[t]{4}{*}{ interpersonal } & Vocative & Oh, soldier, soldier, won't you marry me \\
\hline & $\begin{array}{l}\text { Modal Adjunct } \\
\text { Mood } \\
\text { probability 'how likely?' } \\
\text { 'how obvious?' } \\
\text { usually 'how often?' } \\
\text { 'how typical?' } \\
\text { opinion 'I think' } \\
\text { Comment } \\
\text { admissive 'I admit' } \\
\text { assertive 'I assure you' } \\
\text { presumptive 'how presumptive } \\
\text { desiderative 'how desirable?' } \\
\text { tentative 'how constant?' } \\
\text { validative 'how valid?' } \\
\text { evaluative 'how sensible?' } \\
\text { predictive 'how expected?' }\end{array}$ & $\begin{array}{l}\text { probably, possibly, certainly } \\
\text { perhaps, maybe, of course, surely, obviously } \\
\text { usually, sometimes, always, never } \\
\text { for the most part, seldom, often } \\
\text { in my opinion, from my point of view, personally } \\
\text { frankly, to be honest, to tell you the truth } \\
\text { honestly, really, believe me, seriously } \\
\text { evidently, apparently, no doubt, presumably } \\
\text { (un)fortunately, to my delight, luckily } \\
\text { initially, tentatively, looking back on it } \\
\text { broadly speaking, in general terms, on the whole } \\
\text { wisely, understandably, foolishly, by mistake } \\
\text { to my surprise, as expected, amazingly }\end{array}$ \\
\hline & Finite & Oh, soldier, soldier, won't you marry me \\
\hline & WH-interrogative & who killed Cock Robin? \\
\hline experiential & $\begin{array}{l}\text { topical (Subj., Compl., circumst. } \\
\text { Adj.) }\end{array}$ & who killed Cock Robin? \\
\hline
\end{tabular}

\section{Works Cited}

Collins, Peter C. "Extraposition in English." Functions of Language 1.1 (1984): 1-18.

Davison, Alice. "Syntactic Markedness and the Definition of Sentence Topic." Language 60.4 (1984): 797-846.

Downing, Angela. "The English Modals Reconsidered." Revista Canaria de Estudios Ingleses 12 (1986): 171-80.

Erdmann, P. "On the principle of 'weight' in English." On Language: Rhetorica, Phonologica, Syntactica. A Fetschrift for Robert P. Stockwell from his Friends and Colleagues. in C. Duncan-Rose and T. Vennemann (eds.) Ed. C. D.-Rose and T. Vennemann. London: Routledge, 1988. 325-39.

Francis, Gill. "Thematic Selection and Distribution in Written Discourse." Word 40 (1989): 20122.

Gómez-González, María Ángeles. "The Relevance of Theme in the Textual Organisation of BBC News Reports." Word 45.3 (1994): 293-305. . A Corpus-Based Approach to Theme in Present-Day British English. Towards an Alternative Moderate Functionalist Interpretation. Ph. D. dissertation. U. of Santiago de Compostela. ISBN 84-8121-599-6, 1996.

Halliday, Michael A. K. "Notes on Transitivity and Theme in English, Part 2", Journal of LInguistics 3 (1967): 199-244.

Halliday, Michael A. K. Learning How to Mean: Explorations in the Development of Language. London: Edward Arnold, 1975. 
Halliday, Michael A. K. An Introduction to Functional Grammar. London: Edward Arnold, 1994 (2nd. ed.).

Huddleston, Rodney D. An Introduction to the Grammar of English. Cambridge: University Press, 1984.

Kies, D. "Marked Themes with and without Pronominal Reinforcement, their Meaning and Distribution in Discourse." Pragmatics, Discourse and Text. Ed. E. M. Steiner, and R. Veltman. London: Pinter Publishers, 1988. 47-75.

Mair, C. Infinitival Complement Clauses in English. Cambridge: CUP, 1990.

Martin, James R. "Language, Register and Genre." Language Studies: Children Writing. Ed. F. Christie. Geelong, Vic.: Deakin University Press, 1984a. 21-30,

Martin, James R. "The Development of Register." Developmental Issues in Discourse. J. Fine and R. O. Freeddle. Norwood, NJ: Ablex, 1984b. 1-39.

McCawley, J. The Syntactic Phenomena of English. Chicago: University of Chicago Press, 1988. Quirk, R., S. Greenbaum, G. Leech, and J. Svartvik. A Comprehensive Grammar of the English Language. London: Longman, 1985.

Whittaker, Rachel. "Theme, Processes and the 1994, Realization of Meanings". Thematic Development of English Texts. M. Ghadessy. Ed. M. Ghadessy. London: Cassell, 1985. 105128. 